“ (C) 2017 IEEE. Personal use of this material is permitted. Permission from IEEE must be obtained for all other uses, in any current or future media, including

reprinting/republishing this material for advertising or promotional purposes, creating new collective works, for resale or redistribution to servers or lists, or reuse of any copyrighted component of this work in other works." 


\title{
Detent Force Reduction of an Arc-Linear Permanent Magnet Synchronous Motor by Using Compensation Windings
}

\author{
Bin Li, J. Zhao, X. D. Liu, Y. G. Guo, H. Z. Hu, and Jian Li
}

\begin{abstract}
Arc-linear permanent-magnet synchronous machine (AL-PMSM) is a kind of servo machine used for scanning system to meet the requirements of high positioning accuracy, high response performance and wide scanning range. To reduce the detent force and increase the travel range of the AL-PMSM, a novel hybrid excited AL-PMSM with a normal armature winding and compensation windings is proposed and investigated in this paper. The compensation windings are installed on the end teeth of the primary side. The influence of a compensation direct current is analyzed by the finite element method (FEM). Based on the result of the analysis, a proper compensation current is proposed to reduce the detent force. The result after the compensation is calculated and analyzed by the FEM. In addition, a combination of primary length optimization and current compensation is proposed, the proper formula for the compensation current is deduced, and the result calculated by the FEM is provided. The travel range is investigated in this paper as well. To reduce the detent force of the travel end, a proper current is supplied into the compensation winding, so the detent force of the both end of the travel range is much reduced, and the smooth travel range is increased.
\end{abstract}

Index Terms - permanent magnet linear synchronous motor (PMLSM), detent force, arc-structure, compensation winding, travel range.

\section{INTRODUCTION}

$\mathrm{B}$ ECAUSE of its high velocity, no transmission, large force, wide travel range and rapid dynamic response characteristic, the permanent magnet (PM) linear synchronous motor (PMLSM) is more and more used in commercial, industrial, and military applications [1-5]. For some scanning system and radar system, a rotary motor with gear box is usually adopted to realize the limited angular movement, which brings some drawbacks, such as occupying large space, bringing transmission error and having low response performance. Thus, arc-linear permanent-magnet synchronous machine (AL-PMSM) is needed to realize the direct driving for limited angular movement. However, as one kind of PMLSM, AL-PMSM will also suffer from detent force, which will influence the position accuracy and low speed characteristic.

The detent force is mainly caused by the slot effect and the end effect, and both of them are caused by the reluctance change between PMs and stator teeth. The reason for the slot effect is the same with that in rotary PM machines. Slot effect can be reduced by many different methods, such as skewing, magnet pole pitch optimization, magnet pole shape optimization, fractional slot/pole construction, stator core optimization, magnet shift, employing notches in the stator teeth, closed stator slots, etc. [6-11]. The end effect is caused by the finite length of the primary and secondary sides. To evaluate the detent force caused by these two effects, [12] shows one way to separate the detent forces caused by the slot effect and end effect. The result shows that without optimization, the detent force caused by the end effect is much higher than that caused by the slot effect. The ways to reduce the detent force can be classified into two kinds, one is the sophisticated control strategies of the machines [13-16], and the other is the optimization of the machine structure [17-25], as shown in Fig. 1. [18] analyzed the influence of the primary side length on the detent force, and indicated that the detent force can be greatly reduced by optimization of the length. [19] developed a multiple secondary side PMLSM to reduce the detent force, while [20] developed a multiple primary side PMLSM to reduce the detent force. Auxiliary poles or auxiliary teeth are also widely used to reduce the detent force [21-24]. [25] adopted a complex structure that the PMLSM was divided into three modules, so the detent force of the three modules can be cancelled by each other. However, few researches have considered to combine the control strategy and structure optimization together. [26] used skewed permanent magnets to suppress high order harmonic components and a linearization observer for further diminishing low-order harmonic components, but the motor structure itself is still in a conventional way.

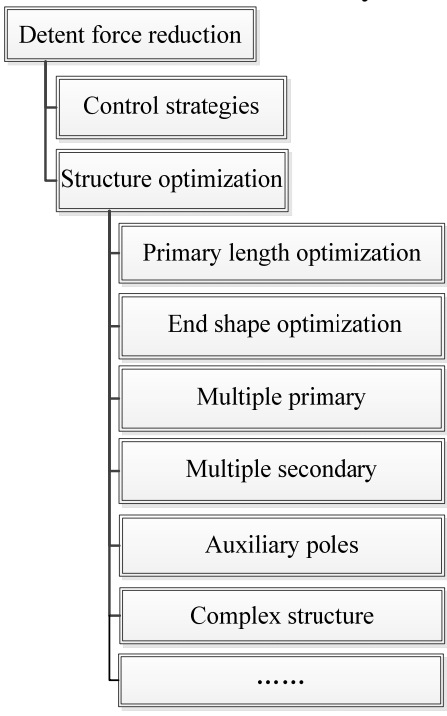

Fig. 1. Detent force minimization techniques

In addition, the PMLSM has both end effects from the primary and secondary sides. However, most of the studies focus on the end effect caused by the short side. The long side end effect will occur when the primary end region is close to the secondary end region. The detent force caused by long side end effect significantly decreases the smooth travel range [26], which should be considered seriously. 
In this paper, a new hybrid excited AL-PMSM with a normal armature winding and compensation windings is proposed and investigated to reduce the detent force and improve the smooth travel range. Firstly, the structure of the hybrid excited AL-PMSM is described. Secondly, the effect of the direct current (DC) compensation is evaluated. Thirdly, the compensation strategy only by using the compensation current is investigated. Fourthly, the combination of length optimization and compensation current is analyzed. Finally, the compensation strategy to increase the smooth travel range is studied.

\section{StRUCtURE AND ANALYSis MOdEL OF THE AL-PMSM}

In this paper, the AL-PMSM adopts short primary and long secondary sides, as shown in Fig. 2. 10-slot/9-pole fractionalslot structure and surface-mounted PM rotor type are adopted. The parameters of the AL-PMSM are listed in Table I.

If no other detent force optimization is used, the fundamental component of the detent force $f_{o d}$ can be expressed as:

$$
f_{\text {od }}=F_{\text {od }} \cos \left(\frac{2 \pi s}{\tau}+\theta\right)
$$

where $s$ is the displacement of the secondary, $\tau$ is the pole pitch, $\theta$ is the offset angle of the original detent force determined by the initial position of the secondary, and $F_{o d}$ is the constant amplitude determined by the structure of the motor.

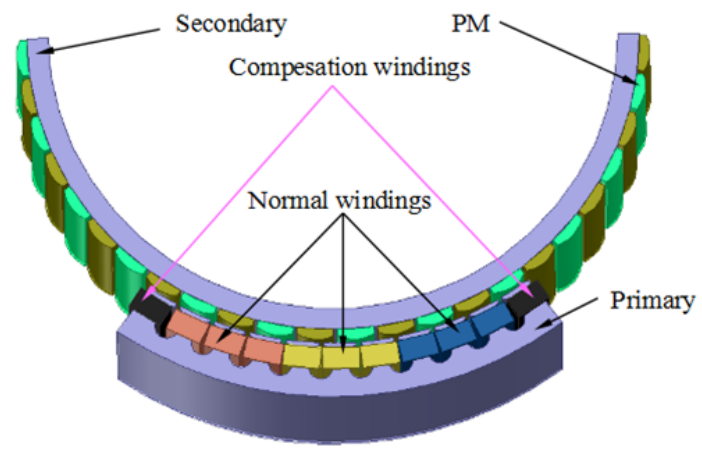

Fig. 2. Diagram of the new hybrid excited AL-PMSM.

TABLE I

SPECIFICATIONS OF THE AL-PMSM

\begin{tabular}{ll}
\hline \hline Parameters & \multicolumn{1}{c}{ Values } \\
\hline Number of phases & 3 \\
Number of poles & 9 \\
Number of slots & 10 \\
Rated thrust & $60 \mathrm{~N}$ \\
Slot-open width & $1.5 \mathrm{~mm}$ \\
Slot pitch & $11.7 \mathrm{~mm}$ \\
Air-gap length & $1 \mathrm{~mm}$ \\
Pole pitch & $13 \mathrm{~mm}$ \\
Height of PM & $3 \mathrm{~mm}$ \\
Material of PM & Nd-Fe-B \\
\hline \hline
\end{tabular}

The detent force calculated by finite element method (FEM) is shown in Fig. 3. It can be seen that the detent force is very large. Thus, two compensation windings are designed on both end teeth of the primary side. During the movement of the secondary, appropriate current is applied into the compensation windings to produce opposite force against the detent force for reducing the total detent force.

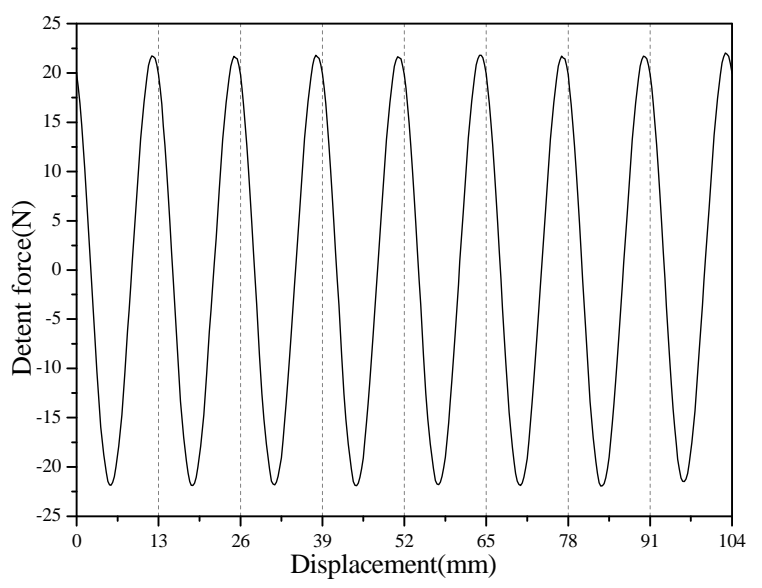

Fig. 3. The detent force without any compensation.

\section{EVALUATION OF THE DC COMPENSATION}

When the secondary is moving, a direct current (DC) of $1 \mathrm{~A}$ is supplied into the compensation windings. To simplify the analysis, only one compensation coil is used at first. The end tooth with the compensation coil can be seen as an electromagnet. When the DC is supplied into one compensation coil, the typical positions and the flux distributions of the primary/secondary are analyzed and calculated by FEM and the results are shown in Fig. 4.

In the position shown in Fig. 4 (a), the $\mathrm{N}$ pole of the equivalent electromagnet faces to the $\mathrm{N}$ pole of $\mathrm{PM}$, and the tangential force generated by DC is 0 . When the secondary moves from position (a) to position (b), the tangential force generated by the DC increases to the maximal value. At position (c), the tangential force generated by DC decreases to 0 again and the $\mathrm{N}$ pole of the equivalent electromagnet faces to the S pole of PM. At position (d), the tangential force generated by DC decreases to the minimal value (negative maximum). Moving from position (d) to position (a), the tangential force generated by DC increases to 0 again.

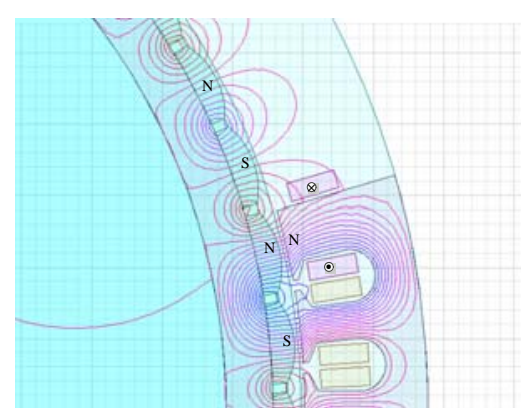

(a) 


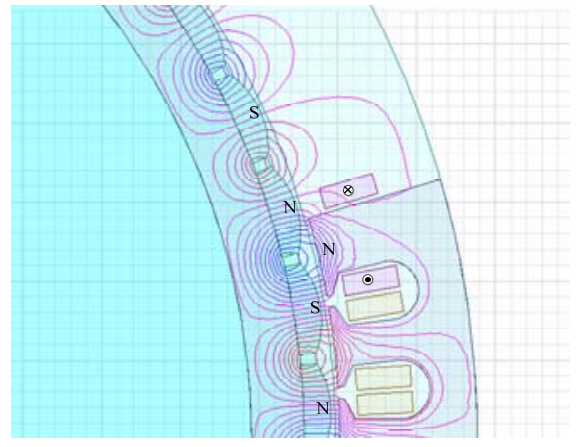

(b)

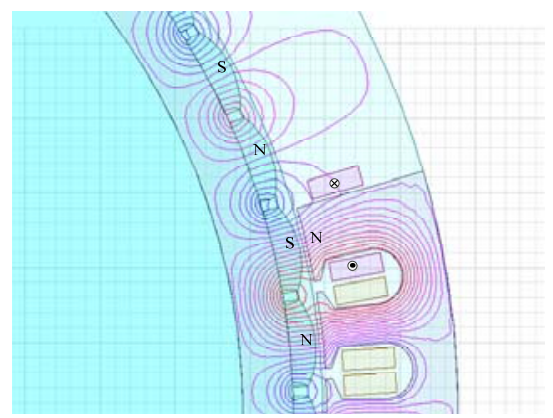

(c)

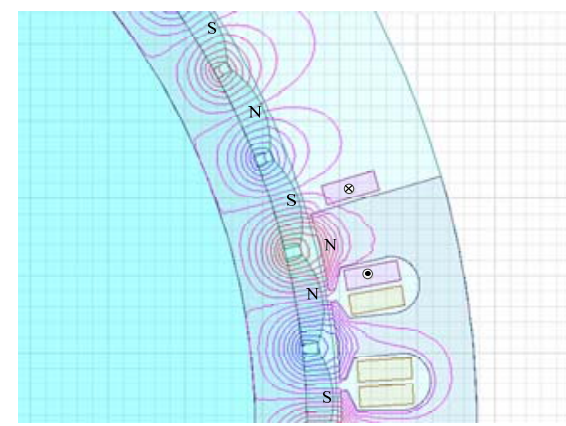

(d)

Fig. 4. The flux distributions at different positions of the primary/secondary.

The detent force calculated by FEM is shown in Fig. 5 . Subtracting the original detent force from the detent force with DC compensation, the tangential force generated by DC can be worked out, as shown in Fig. 6. It can be seen from Fig. 6 that the tangential force generated by DC changes periodically with every two pole pitches $(26 \mathrm{~mm})$, which is coincident with the analysis. The four positions shown in Fig. 4 are marked in Fig. 6 as a, b, c, and d, respectively.

Fig. 7 shows the tangential force generated by DC in the other compensation winding, where the amplitude and frequency are the same with those of the force generated by the first winding, and the only difference is the phase angle.

Based on the above analysis, the force generated by DC $f_{d c}$ can be expressed as:

$$
f_{d c}=F_{d c} \cos \left(\frac{\pi s}{\tau}+\theta_{d c}\right)
$$

where $\theta_{d c}$ is the offset angle determined by the initial position of the secondary, and $F_{d c}$ is the constant amplitude determined by the structure of the motor considering the DC compensation.

It is this knowledge which provides the key to compensate the detent force with appropriate current.

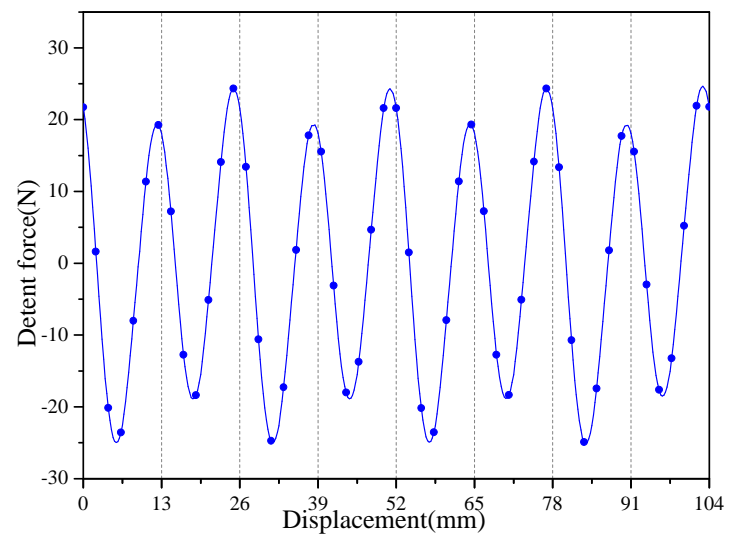

Fig. 5. The detent force with DC compensation.

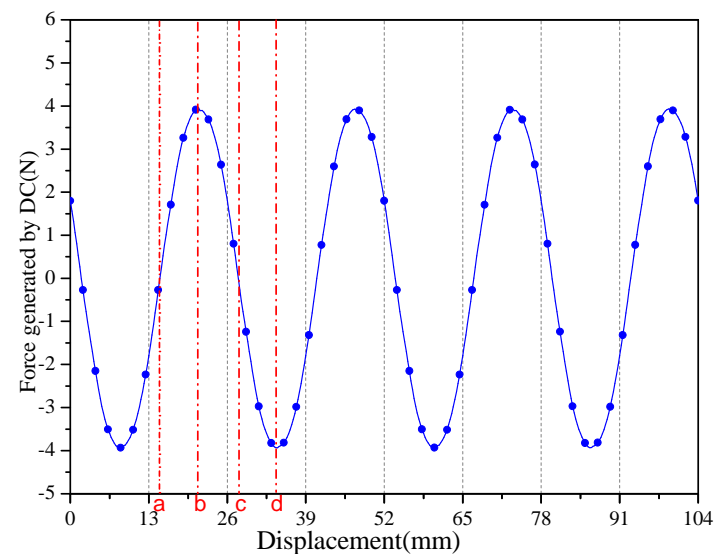

Fig. 6. Tangential force generated by $1 \mathrm{~A}$ DC in the first compensation winding.

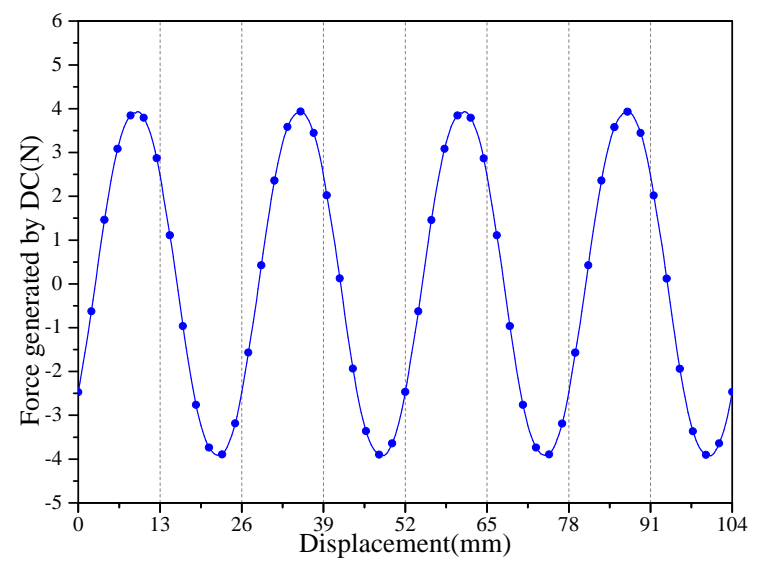

Fig. 7. Tangential force generated by $1 \mathrm{~A} \mathrm{DC}$ in the other compensation winding.

\section{DETENT FORCE COMPENSATION}

\section{A. Compensation only by current}

Comparing equations (1) and (2), it can be seen that the frequency of the force generated by DC is half the value of the frequency of the original detent force. If an alternating current with the same frequency of the force generated by DC is applied to the compensation coil, its formula is,

$$
i_{a c}=I_{a c} \cos \left(\frac{\pi s}{\tau}+\theta_{a c}\right)
$$

where $I_{a c}$ is the amplitude of the current, and $\theta_{a c}$ is the initial 
phase of the current.

According to homogeneous theorem, the force $f_{a c}$ generated by this alternating current can be expressed as:

$$
\begin{aligned}
& f_{a c}=f_{d c} \cdot i_{a c} \\
& =F_{d c} \cos \left(\frac{\pi s}{\tau}+\theta_{d c}\right) \cdot I_{a c} \cos \left(\frac{\pi s}{\tau}+\theta_{a c}\right) \\
& =F_{d c} \cdot I_{a c} \cdot \frac{1}{2} \cdot\left[\cos \left(\frac{2 \pi s}{\tau}+\theta_{d c}+\theta_{a c}\right)+\cos \left(\theta_{d c}-\theta_{a c}\right)\right]
\end{aligned}
$$

It can be seen that $\cos \left(\theta_{d c}-\theta_{a c}\right)$ is a constant, so the frequency of $f_{a c}$ is the same with the frequency of original detent force $f_{o d}$. If the phase difference between $f_{a c}$ and $f_{o d}$ is $\pi$, and their amplitudes are the same, i.e.,

$$
\left\{\begin{array}{l}
\theta_{d c}+\theta_{a c}=\theta+\pi \\
F_{d c} \cdot I_{a c} \cdot \frac{1}{2}=F_{o d}
\end{array}\right.
$$

then the detent force can be eliminated.

Based on the above analysis, the amplitude and phase of the compensation current can be calculated:

$$
\begin{gathered}
\theta_{a c}=\theta+\pi-\theta_{d c} \\
I_{a c}=\frac{2 F_{o d}}{F_{d c}}
\end{gathered}
$$

Thus, the resultant detent force $f_{d}$ of the force generated by the compensation current and the original detent force $f_{\text {od }}$ can be expressed as:

$$
f_{d}=f_{o d}+f_{a c}=F_{d c} \cdot I_{a c} \cdot \frac{1}{2} \cdot \cos \left(\theta_{d c}-\theta_{a c}\right)
$$

From formula (8), it can be seen that $f_{d}$ is a constant value. The result calculated by FEM is shown in Fig. 8. The fundamental component of the detent force is eliminated, but the remaining detent force is oscillating around $f_{d}$ because of the harmonic component.

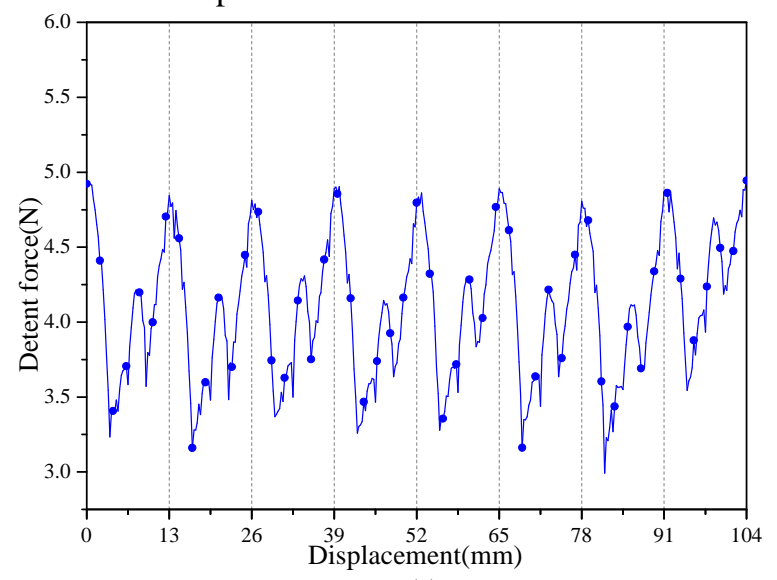

(a)

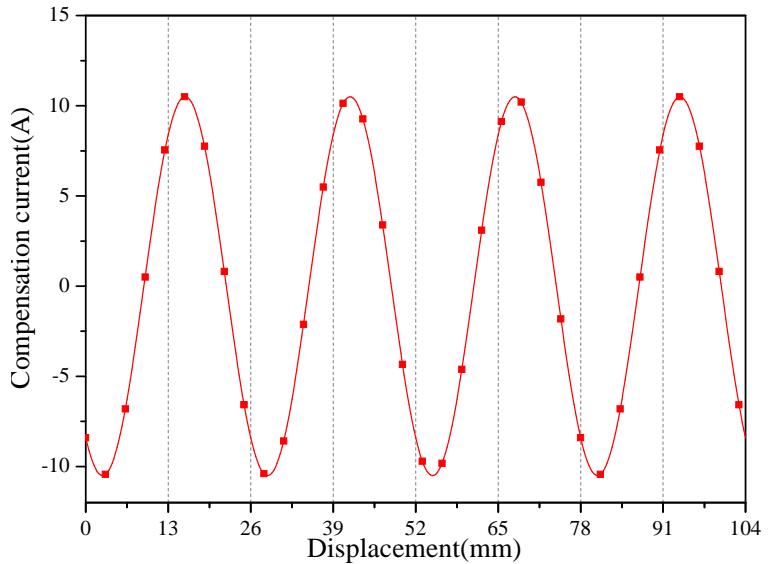

(b)

Fig. 8. The detent force result and the compensation current: (a) detent force, (b) compensation current.

It can be seen that by applying an appropriate alternating current into the compensation coil, the peak-peak value of detent force can be reduced from $43.5 \mathrm{~N}$ to $1.8 \mathrm{~N}$, i.e. by 95.9\%. However, there exist two problems. First, the compensation current is very large. Second, because of the constant value of the resultant force $f_{d}$, the thrust will be influenced by this resultant force, and the designed rated thrust will be changed.

The amplitude and frequency of the force generated by the two compensation coils with DC are the same, and the only difference is the phase angle. Therefore, if both compensation windings are used, the amplitude of the compensation current can be reduced to half value, but the constant component will remain unchanged.

Fig. 9 shows the rated thrusts before and after the compensation with $i_{a c}$. It can be seen that after the compensation, the force ripple is much reduced from $66 \%$ to $3.3 \%$ and the average thrust has increased from $60 \mathrm{~N}$ to $65 \mathrm{~N}$. This increase of the average thrust will influence the accuracy of the open loop thrust control. However, it can be compensated by the control system, though this may increase the complexity of the control strategy.

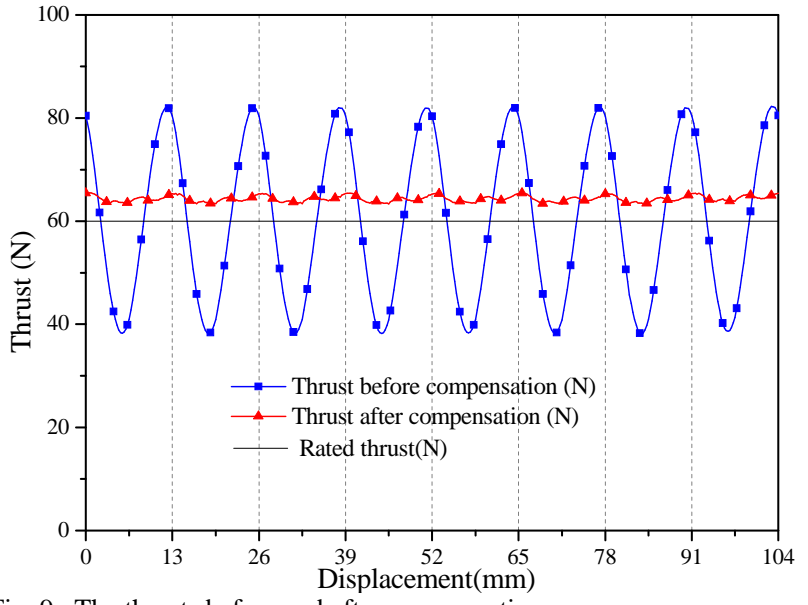

Fig. 9. The thrusts before and after compensation.

\section{B. Combination of primary length optimization and current compensation}

As known, the detent force can be greatly reduced by 
optimizing the length of the primary [12], and this is a very easy way to fulfill. Here, the length of the primary is optimized by changing the length of the end teeth. After the optimization of the length, the fundamental component of the detent force without compensation current is eliminated. The remaining detent force is shown in Fig. 10.

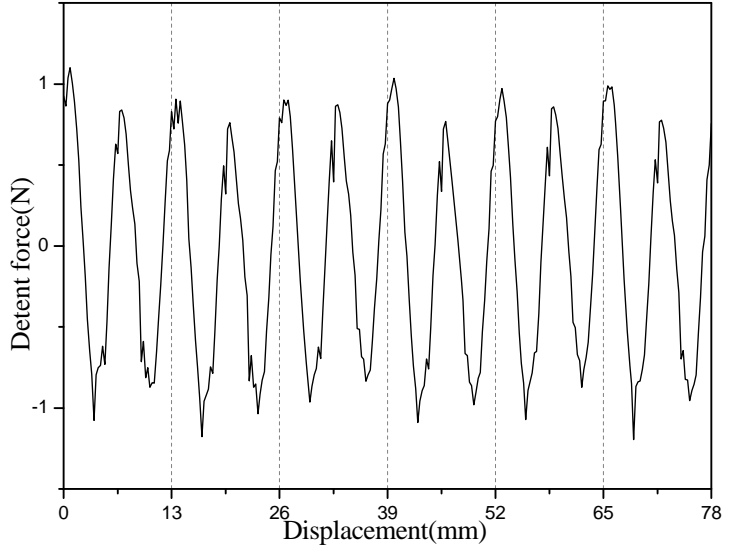

Fig. 10. The detent force after preliminary length optimization.

Fig. 11 (a) and Fig. 11 (b) show the harmonics of the detent force before and after the primary length optimization, respectively. It can be seen that the first harmonic is greatly reduced and the second harmonic becomes the main component of the detent force after the optimization.

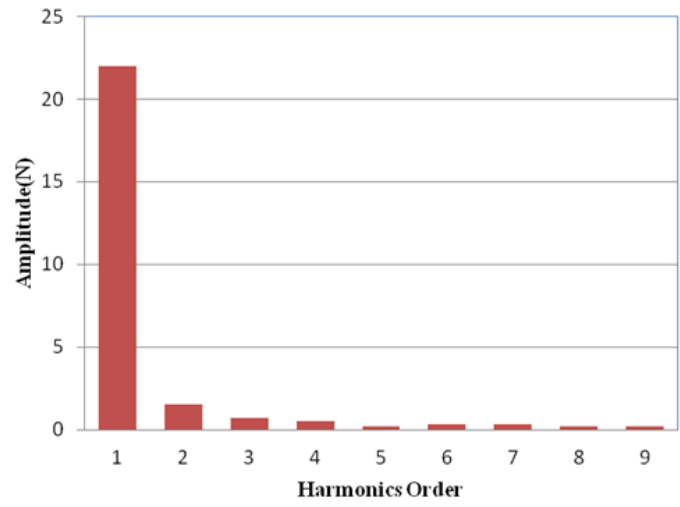

(a)

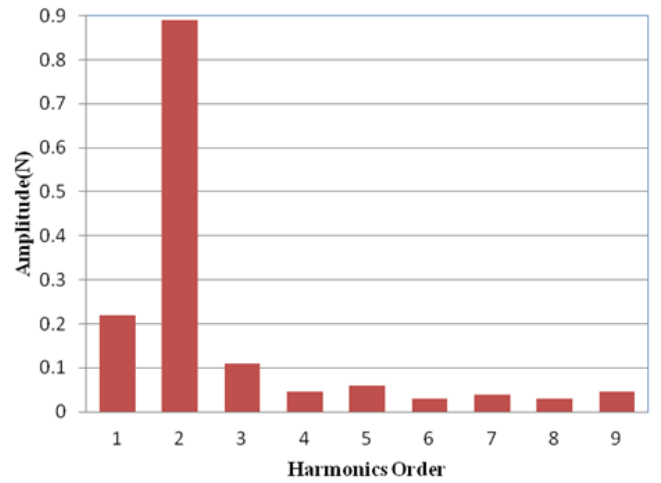

(b)

Fig. 11. The harmonics before and after preliminary length optimization.

The second harmonic of the detent force can be expressed as:

$$
f_{\text {od } 2}=F_{o d 2} \cdot \cos \left(\frac{4 \pi s}{\tau}+\theta_{2}\right)
$$

where $\theta_{2}$ is the offset angle of the detent force with the primary length optimization and without compensation current, and $F_{o d 2}$ is the constant amplitude with the primary length optimization and without compensation current.

It can be seen that the frequency of the remaining main component of the detent force is double of the original frequency. It is this knowledge which provides the key to reduce the resultant detent force further.

Fig. 12 shows the detent force with 1 A DC compensation after preliminary length optimization, and Fig. 13 shows the tangential force generated by the $1 \mathrm{~A}$ DC. It can be seen that the force generated by DC changes periodically with every two pole pitches (26 mm). Compared to Fig. 6, the amplitude and frequency are the same, and only the offset angle has small difference because of the slight length change of the primary.

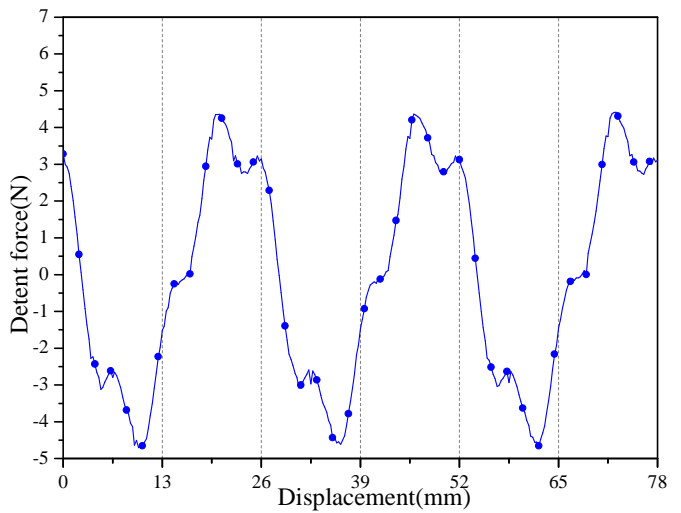

Fig. 12. The detent force with DC compensation after preliminary length optimization.

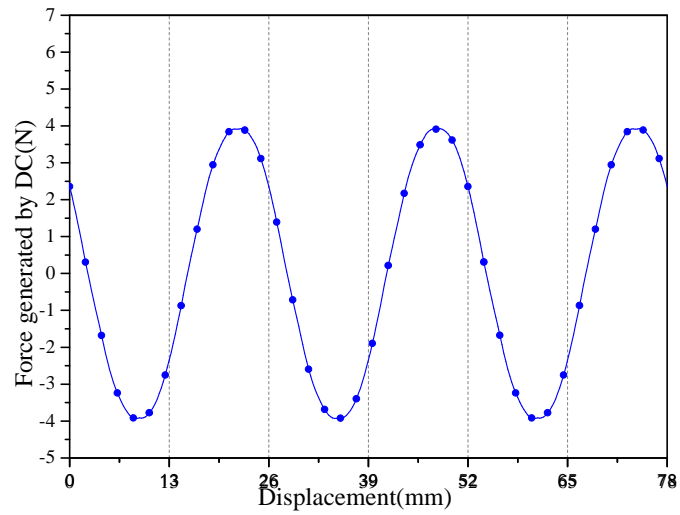

Fig. 13. Tangential force generated by 1A DC with length optimization.

If a current

$$
i_{c}=i_{a c} \cdot i_{a c}^{\prime}=I_{a c} \cdot \cos \left(\frac{\pi s}{\tau}+\theta_{a c}\right) \cdot I_{a c}^{\prime} \cdot \cos \left(\frac{2 \pi s}{\tau}+\theta_{a c}^{\prime}\right)
$$

is applied to the compensation coil, the force generated by this current can be expressed as:

$f_{c}=f_{d c} \cdot i_{c}$

$=F_{d c} \cos \left(\frac{\pi s}{\tau}+\theta_{d c}\right) \cdot I_{a c} \cdot \cos \left(\frac{\pi s}{\tau}+\theta_{a c}\right) \cdot I_{a c}^{\prime} \cdot \cos \left(\frac{2 \pi s}{\tau}+\theta_{a c}^{\prime}\right)$

$=F_{d c} \cdot I_{a c} \cdot \frac{1}{2} \cdot\left[\cos \left(\frac{2 \pi s}{\tau}+\theta_{d c}+\theta_{a c}\right)+\cos \left(\theta_{d c}-\theta_{a c}\right)\right] \cdot I_{a c}^{\prime} \cdot \cos \left(\frac{2 \pi s}{\tau}+\theta_{a c}^{\prime}\right)$

If $\theta_{a c}$ is adjusted to satisfy 


$$
\theta_{d c}-\theta_{a c}=\frac{\pi}{2}
$$

Then

$$
\cos \left(\theta_{d c}-\theta_{a c}\right)=0
$$

The equation can be simplified as:

$$
\begin{aligned}
& f_{c}=F_{d c} \cdot I_{a c} \cdot \frac{1}{2} \cdot \cos \left(\frac{2 \pi s}{\tau}+\theta_{d c}+\theta_{a c}\right) \cdot I_{a c}^{\prime} \cdot \cos \left(\frac{2 \pi s}{\tau}+\theta_{a c}^{\prime}\right) \\
& =\frac{1}{4} F_{d c} \cdot I_{a c} \cdot I_{a c}^{\prime} \cdot\left[\cos \left(\frac{4 \pi s}{\tau}+\theta_{d c}+\theta_{a c}+\theta_{a c}^{\prime}\right)+\cos \left(\theta_{d c}+\theta_{a c}-\theta_{a c}^{\prime}\right)\right]
\end{aligned}
$$

It can be seen that $\cos \left(\theta_{d c}+\theta_{a c}-\theta_{a c}^{\prime}\right)$ is a constant, so the frequency of $f_{c}$ is the same with the frequency of the detent force $f_{o d 2}$, then if $\theta_{a c}, I_{a c}$ and $I_{a c}{ }^{\prime}$ are adjusted to suitable values, $f_{\text {od } 2}$ can be eliminated by $f_{c}$.

Based on the above analysis, the amplitude and phase of the compensation current can be calculated by

$$
\left\{\begin{array}{l}
\theta_{d c}-\theta_{a c}=\frac{\pi}{2} \\
\theta_{a c}+\theta_{a c}^{\prime}=\theta_{2}+\pi-\theta_{d c} \\
I_{a c} \cdot I_{a c}^{\prime}=\frac{4 \cdot F_{o d 2}}{F_{d c}}
\end{array}\right.
$$

So the resultant force can be expressed as:

$$
f_{d}^{\prime}=f_{o d 2}+f_{c}=\frac{1}{4} F_{d c} \cdot I_{a c} \cdot I_{a c}^{\prime} \cdot \cos \left(\theta_{d c}+\theta_{a c}-\theta_{a c}^{\prime}\right)
$$

Therefore, the resultant force $f_{d}^{\prime}$ is a constant value. The result calculated by FEM is shown in Fig. 14. The fundamental component of the detent force is eliminated. However, because of the harmonic component, the remaining detent force is oscillating around $f_{d}$ '.

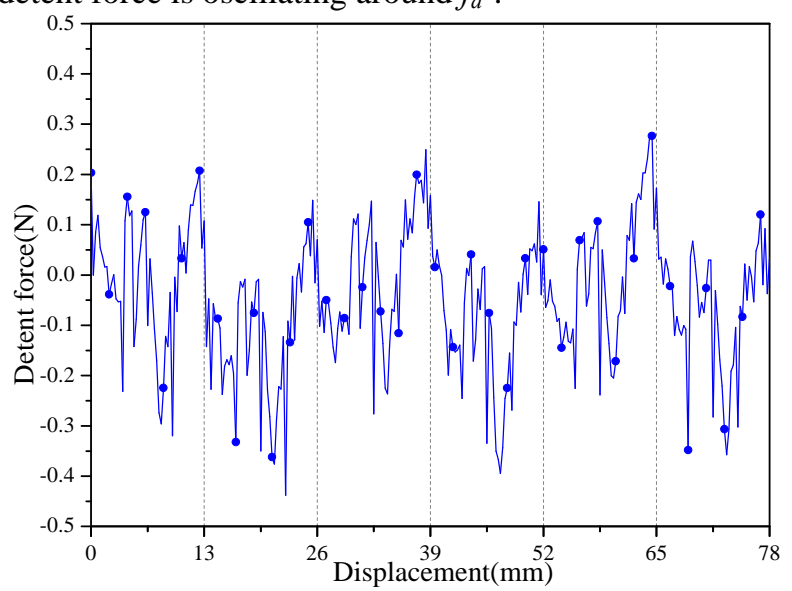

(a)

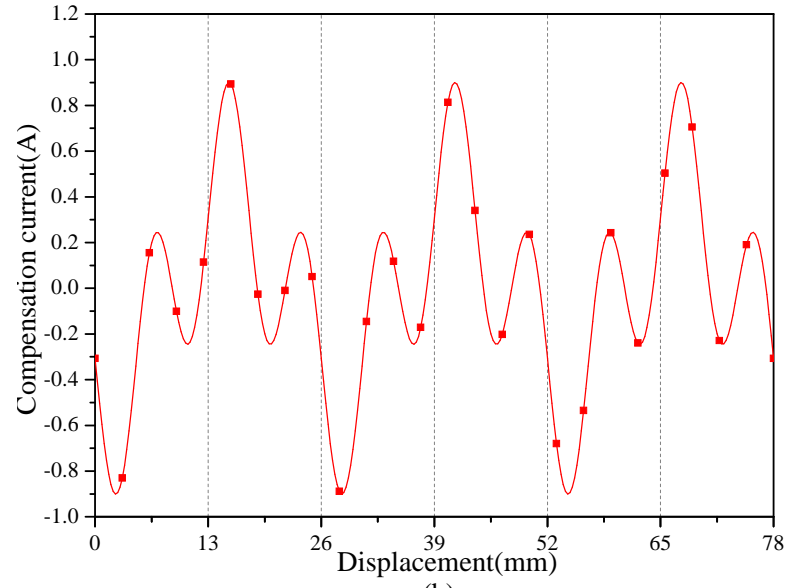

(b)

Fig. 14. The detent force result and compensation current with one coil: (a) detent force, (b) compensation current.

It can be seen that by applying an appropriate current into the compensation coil, the peak-peak detent force can be reduced from $2.1 \mathrm{~N}$ to $0.7 \mathrm{~N}$ by $66.7 \%$. Compared with the result only using current compensation, the amplitude of the compensation current has reduced from 10.5 A to 0.9 A.

Based on the above analysis, if both windings are used, the amplitude of the compensation current for each winding can be reduced to half value, but the constant value of the resultant force $f_{d}$ ' will remain unchanged. The result is shown in Fig. 15. It can be seen that the result calculated by FEM agrees with the above analysis.

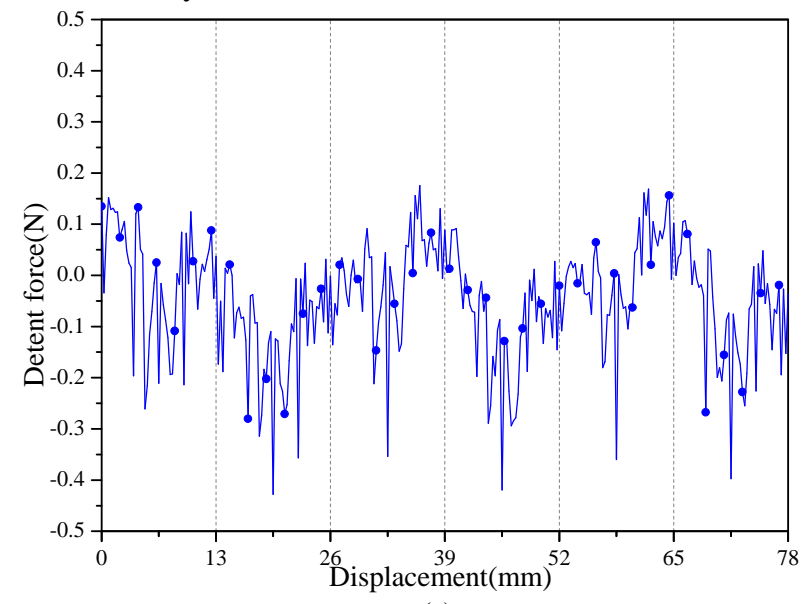

(a)

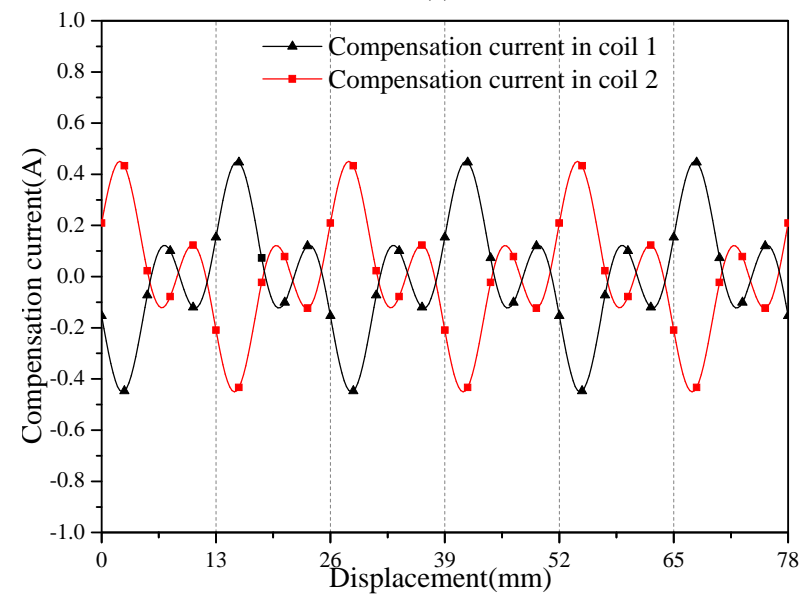


(b)

Fig. 15. The detent force result and compensation current with both coils: (a) detent force, (b) compensation current.

Fig. 16 shows the resultant detent thrusts before and after current compensation. It can be seen that because the amplitude of the compensation current is much reduced, the constant value of the resultant detent force is very small, and the influence on the designed thrust is negligible.

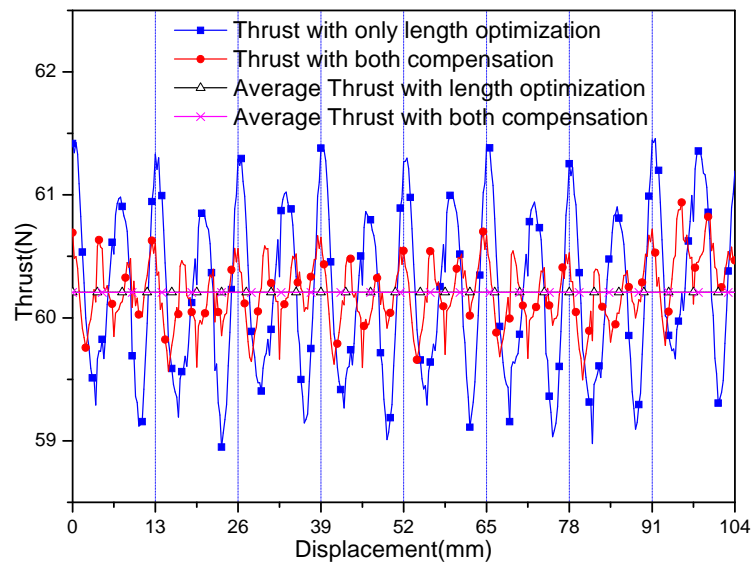

Fig. 16. The thrusts before and after compensation.

\section{OPTIMIZATION OF THE TRAVEL RANGE}

The travel range is very important for the AL-PMSM used for scanning system with limit space. However, because of the end effect of the secondary, when the secondary end is close to the primary end, the thrust characteristic deteriorates seriously. Fig. 17 shows the thrust when the secondary end is leaving the primary end. It can be seen that the influence of secondary end effect is mainly at two pole pitches $(26 \mathrm{~mm})$, and the amplitude of cogging force during the first pole pitch is the largest. The cogging force caused by secondary end effect significantly decreases the smooth travel range of the AL-PMSM by more than one pole pitch.

Fig. 18 shows the detent force with 1 A DC compensation during this travel range. Fig. 19 shows the tangential force generated by the $1 \mathrm{~A}$ DC. It can be seen that during the first pole pitch of the travel range, there are some distortions. Comparing Fig. 17 with Fig. 19, during the beginning of the travel range $(0-15 \mathrm{~mm})$, the shape of the cogging force and that of the force generated by DC appear similar. Thus, if an appropriate DC is applied to the compensation coil during the beginning of the travel range, the cogging torque can be reduced.

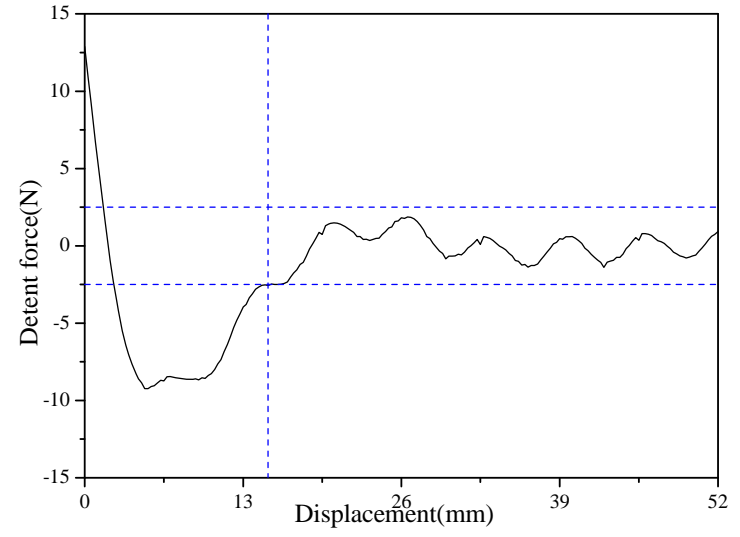

Fig. 17. Cogging force waveform during the beginning of the travel range.

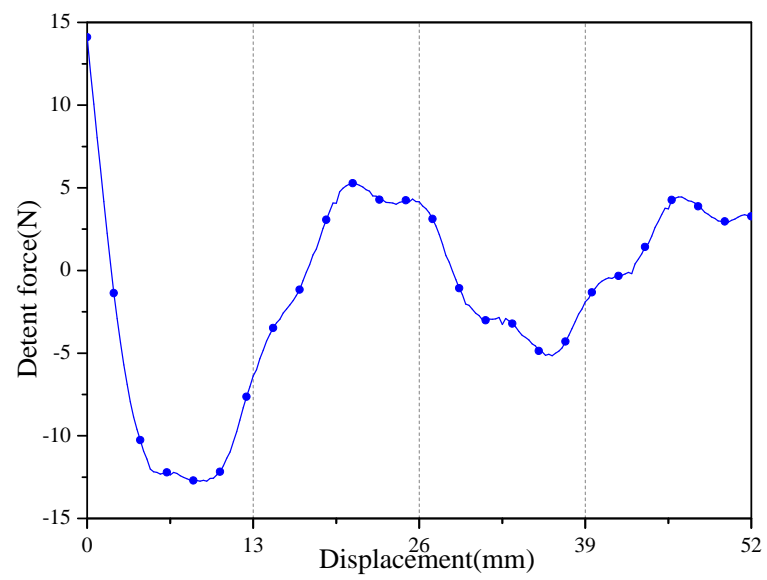

Fig. 18. Cogging force waveform during the beginning of the travel range with DC compensation.

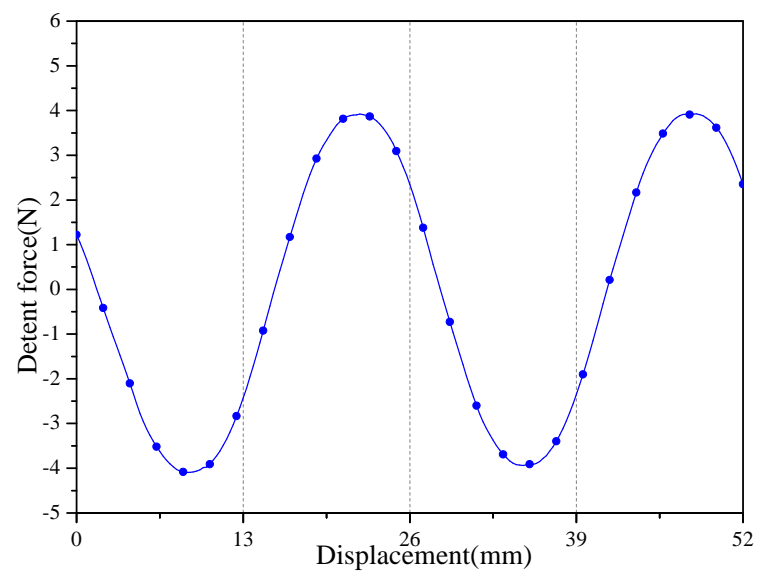

Fig. 19. Tangential force generated by $1 \mathrm{~A}$ DC during the beginning of the travel range.

Fig. 20 shows the cogging force waveforms with different compensation currents. The duration of the compensation current is the first $15 \mathrm{~mm}$ of the travel range. With the optimum value of $2.7 \mathrm{~A}$, the detent force is much reduced from $9.2 \mathrm{~N}$ to $2.5 \mathrm{~N}$ by $73 \%$.

Fig. 21 (a) shows the thrust during the whole travel range with and without current compensation. And Fig. 21 (b) shows the compensation current during the whole travel range. It can be seen that if the acceptable detent force is $5 \%$ of the rated 
thrust, then the travel range can be increased from $160 \mathrm{~mm}$ to $176 \mathrm{~mm}$ by $10 \%$.

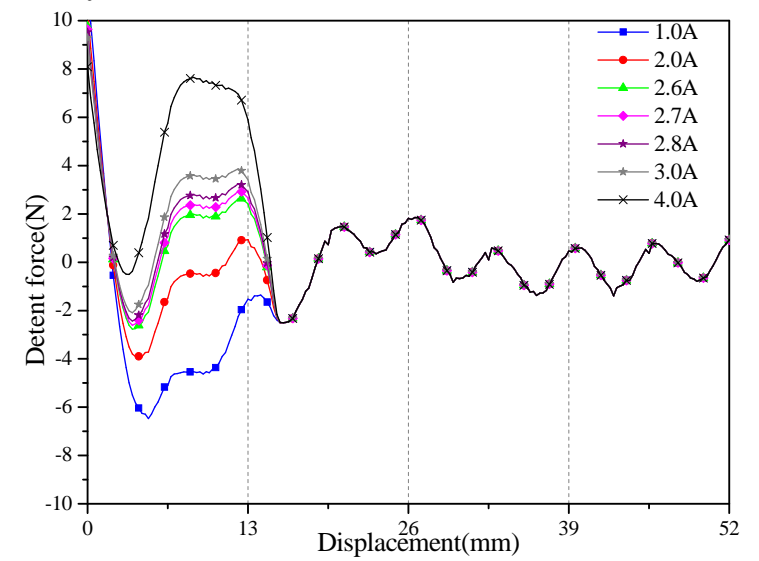

Fig. 20. Cogging force waveforms with different compensation currents.

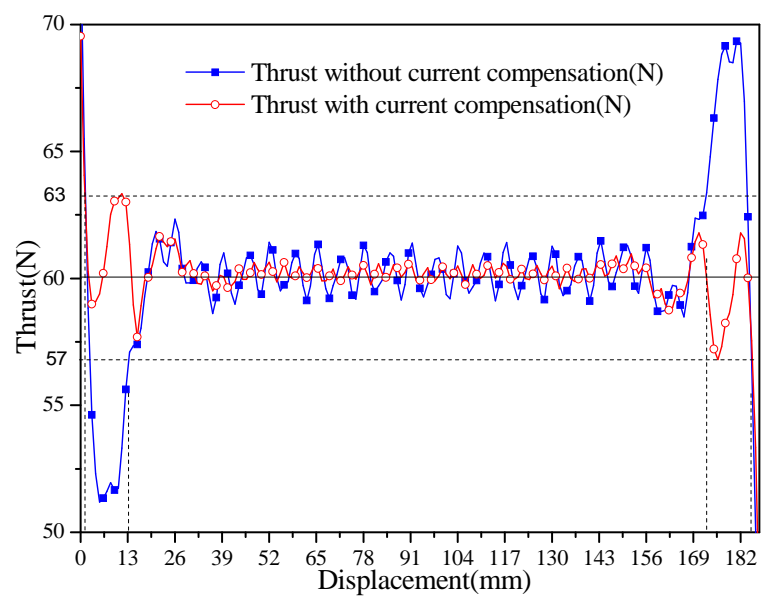

(a)

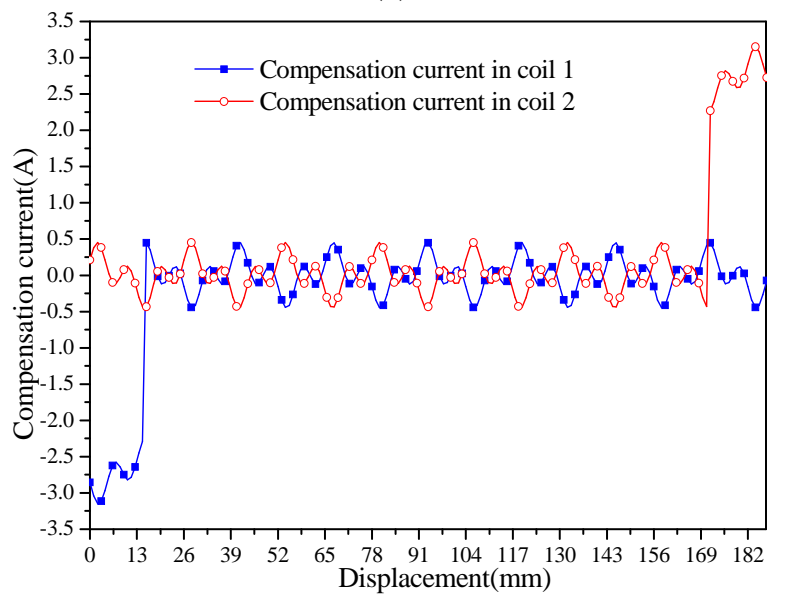

(b)

Fig. 21. Thrust during the whole travel range and the compensation current: (a) thrust, (b) compensation current.

\section{VALIDATION BY EXPERIMENT}

To validate the analytical and FEM results of the ALPMSM, the AL-PMSM prototypes with and without the primary length optimization are manufactured and the experiment platform is built, as shown in Fig. 22. In order to test the AL-PMSM prototype more conveniently, the arc primary and secondary are installed in a round housing unit. A hand wheel is installed to turn the secondary manually. A harmonic gear is installed between the hand wheel and the secondary to get a precise position. An absolute encoder with the precision of $0.01^{\circ}$ is installed on the secondary to show the position. The thrust is measured by a torque sensor with the full scale of $5 \mathrm{Nm}$ and precision of $0.1 \%$. The AL-PMSM shaft is placed vertically to avoid the influence of gravity.

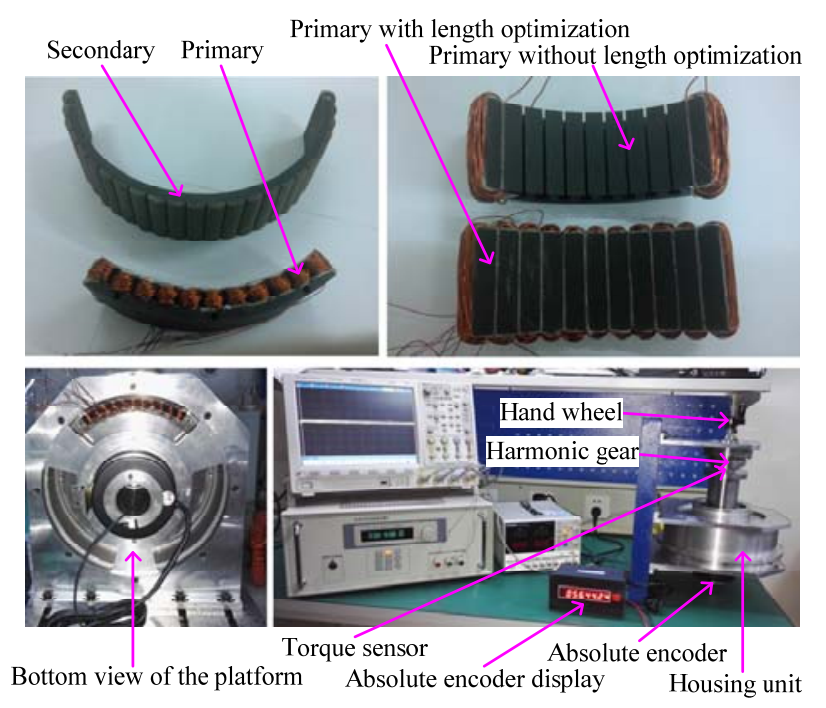

Fig. 22. The experiment platform for AL-PMSM prototypes.

First of all, the AL-PMSM prototype without primary length optimization is tested during the middle operating range. In different positions, corresponding current with the value shown in Fig. 8 is applied into the compensation winding. Fig. 23 shows the detent forces before and after current compensation obtained by FEM and experiment. It can be seen that the peak-peak value of detent force can be reduced from $43.2 \mathrm{~N}$ to $1.5 \mathrm{~N}$ by $95.8 \%$ in the experiment. Then the AL-PMSM prototype with both length optimization and current compensation is tested during the middle operating range. In different positions, corresponding current with the value shown in Fig. 14 is applied into the compensation winding. The comparison of detent force before and after compensation obtained by FEM and experiment is shown in Fig. 24. In this situation, it can be seen that the peak-peak value of detent force can be reduced from $2.0 \mathrm{~N}$ to $0.9 \mathrm{~N}$ by $65 \%$ in the experiment. The experiment of optimization during the end operating range is also carried out and the result is shown in Fig. 25. In this test, a DC current of 2.7A is applied into the compensation winding during the first $15 \mathrm{~mm}$ travel range. It can be seen that the detent force is much reduced from $9.1 \mathrm{~N}$ to $3.7 \mathrm{~N}$ by $59 \%$. And the effective travel range is increased. Good agreement between the FEM simulation result and experimental result verifies the validity of the proposed compensation method. 


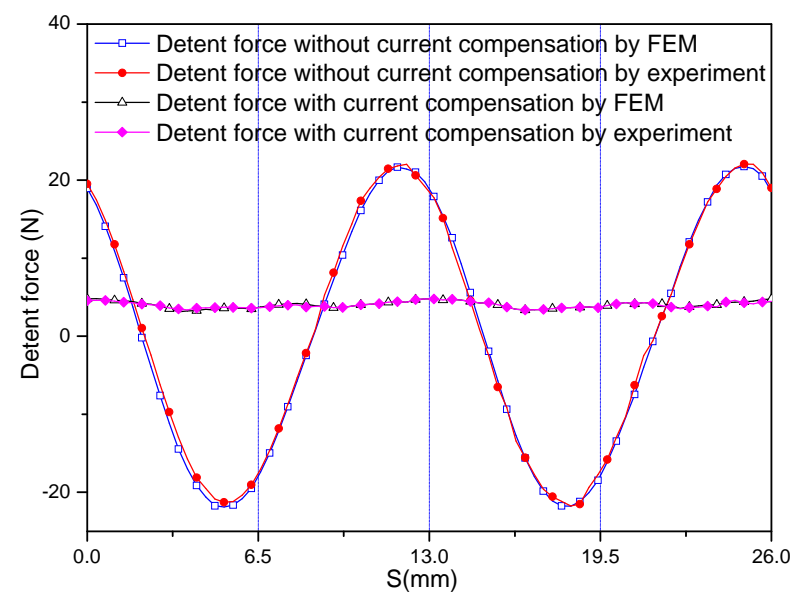

Fig. 23. The experiment result before length optimization.

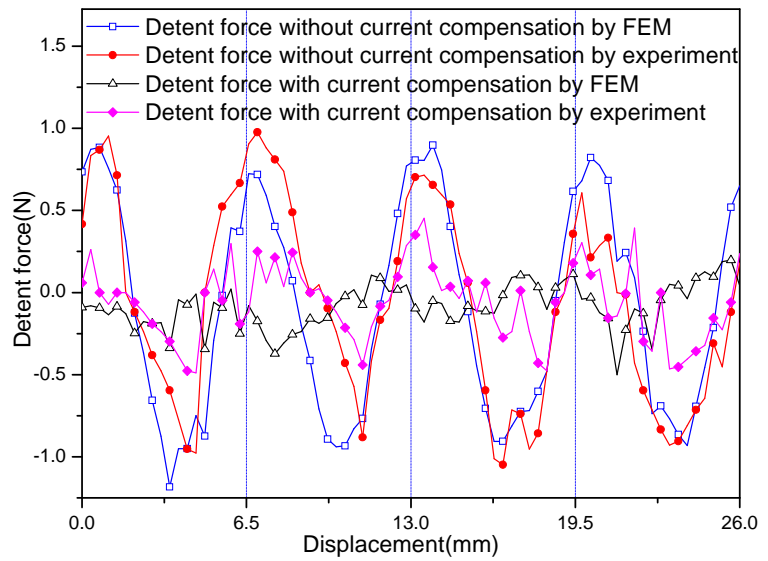

Fig. 24. The experiment result after length optimization.

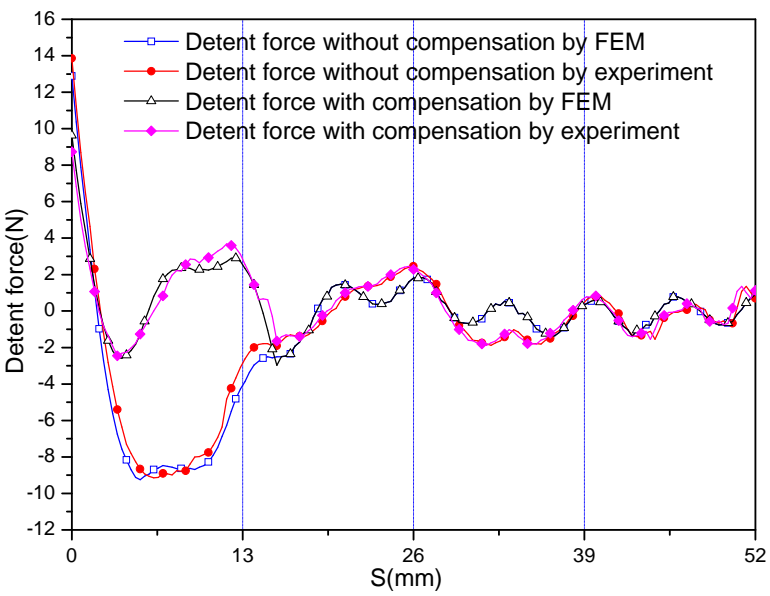

Fig. 25. The experiment result of the travel range optimization.

\section{CONCLUSIONS}

A novel hybrid excited AL-PMSM with a normal armature winding and compensation windings is proposed and studied in this paper. The influence of a direct compensation current is analyzed by the FEM. The proper compensation current is deduced based on the analysis. The result calculated by the FEM shows that by only using the compensation winding, the detent force can be reduced by $95.9 \%$, but the compensation current is very large, and the rated thrust will be influenced by the resultant force, so using this method only is not satisfactory enough. Therefore, the combination of primary length optimization and current compensation is proposed. The result calculated by the FEM shows that after the length optimization, the detent force is reduced from $\pm 22 \mathrm{~N}$ to $\pm 1 \mathrm{~N}$. By applying an appropriate current into the compensation coil, the detent force can be further reduced by $66.7 \%$. Compared with the result by only using current compensation, the amplitude of the compensation current is reduced from 10.5A to $0.9 \mathrm{~A}$, and the constant value of the resultant force becomes very small, and will not change the rated force much. By using a direct compensation current during the end travel range, the detent force at this range is reduced from $9.2 \mathrm{~N}$ to $2.5 \mathrm{~N}$, and the travel range with thrust ripple of $5 \%$ can be increased from $160 \mathrm{~mm}$ to $176 \mathrm{~mm}$ by $10 \%$ without influencing the average thrust. Prototypes and test platform are built and experiments are conducted to validate the effectiveness of the proposed compensation method. Good agreement is obtained between the FEM and experimental results. If the current is controlled with a closed-loop controlling system, the result could be even better. This will be done in the future research. Although the model in this paper is an AL-PMSM, the conclusions can be used for normal PMLSM as well, because all the analyses are based on the same principle.

\section{REFERENCES}

[1] R. W. Cao, M. Cheng, C. C. Mi, and W. Hua, "Influence of leading design parameters on the force performance of a complementary and modular linear flux-switching permanent-magnet motor," IEEE Trans. Ind. Electron., vol. 61, no. 5, pp. 2165-2175, May 2014.

[2] L. Cappelli, Y. Coia, F. Marignetti, and Z. Q. Zhu, "Analysis of eccentricity in permanent-magnet tubular machines," IEEE Trans. Ind. Electron., vol. 61, no. 5, pp. 2208-2216, May 2014.

[3] M. Ma, L. Li, Z. He, and C. C. Chan, "Influence of longitudinal endeffects on electromagnetic performance of a permanent magnet slotless Linear Launcher,” IEEE Trans. Plasma Sci., vol. 41, no. 5, pp. 11611166, 2013.

[4] S.-G. Lee, S.-A. Kim, S. Saha, Y.-W. Zhu, and Y.-H. Cho, "Optimal structure design for minimizing detent force of PMLSM for a ropeless elevator,” IEEE Trans. Magn., vol. 50, no. 1, art. 4001104, 2014.

[5] F. Cupertino, P. Giangrande, G. Pellegrino, and L. Salvatore, "End effects in linear tubular motors and compensated position sensorless control based on pulsating voltage injection,” IEEE Trans. Ind. Electron., vol. 61, no. 5, pp. 2208-2216, May 2014.

[6] Y. Zhou, H. S. Li, G. W. Meng, S. Zhou, and Q. Cao, "Analytical calculation of magnetic field and cogging torque in surface-mounted permanent-magnet accounting for any eccentric rotor shape," IEEE Trans. Ind. Electron., vol. 62, no. 6, pp. 3438-3447, Jun. 2015.

[7] L. J. Wu, Z. Q. Zhu, D. A. Staton, M. Popescu, and D. Hawkins, "Comparison of analytical models of cogging torque in surface-mounted PM machines," IEEE Trans. Ind. Electron., vol. 59, no. 6, pp. 24142425, Jun. 2012.

[8] W .Q. Chu and Z. Q. Zhu, "Investigation of torque ripples in permanent magnet synchronous machines with skewing," IEEE Trans. Magn., vol. 49, no. 3, pp. 1211-1220, 2013.

[9] H. Hong and J. Yoo, "Shape design of the surface mounted permanent magnet in a synchronous machine," IEEE Trans. Magn., vol. 47, no. 8, pp. 2109-2117, Aug. 2011.

[10] L. Dosiek and P. Pillay, "Cogging torque reduction in permanent magnet machines,” IEEE Trans. Ind. Appl., Vol.43, no.6, pp.1565-1570, Nov. 2007.

[11] P. Zheng, J. Zhao, et al., "Optimization of the magnetic pole shape of a permanent-magnet synchronous motor," IEEE Trans. Magn., vol. 43, no. 6, pp. 2531-2533, 2007.

[12] H. Hu, J. Zhao, X. Liu, Z. Chen, Z. Gu, and Y. Sui, "Research on the torque ripple and scanning range of an arc-structure PMSM used for 
scanning system,” IEEE Trans. Magn., vol. 50, no. 11, art. 8105504, 2014.

[13] K. Cho, J. Kim, S. B. Choi, and S. Oh, "A high-precision motion control based on a periodic adaptive disturbance observer in a PMLSM," IEEEASME Trans. Mechatron., vol. 20, no. 5, pp. 2158-2171, 2015.

[14] Y. Zhu, S.-M. Jin, K.-S. Chung, and Y.-H. Cho, "Control-based reduction of detent force for permanent magnet linear synchronous motor," IEEE Trans. Magn., vol. 45, no. 6, pp. 2827-2830, Jun. 2009.

[15] D.-Y. Lee and G.-T. Kim, "Design of thrust ripple minimization by equivalent magnetizing current considering slot effect," IEEE Trans. Magn., vol. 42, no. 4, pp. 1367-1370, Apr. 2006.

[16] P. G. Panah, A. Shafiei, A. Parsa Pour, and B. Mirzaeian Dehkordi, "Velocity control of a PMLSM using a brain emotional learning based intelligent control strategy," in Proc. 2011 IEEE Int. Conf. on System Engineering and Technology (ICSET), 2011, pp. 47-52.

[17] R. Cao, M. Cheng, and W. Hua. "Investigation and general design principle of a new series of complementary and modular linear FSPM motors," IEEE Trans. Ind. Electron., vol. 60, no. 12, pp. 5436-5446, Dec. 2013.

[18] Z. Q. Zhu, Z. P. Xia, D. Howe, and P. H. Mellor, "Reduction of cogging force in slotless linear permanent magnet motors," IEE Proceedings Electric Power Applications, vol. 144, no. 4, pp. 277-282, 1997

[19] Bao-quan Kou, W. Hong-Xing, Li-yi Li, Z. Liang-Liang, Z. Zhe, and C. Hai-Chuan, "The thrust characteristics investigation of double-side plate permanent magnet linear synchronous motor for EML," IEEE Trans. Magn., vol. 45, no. 1, pp. 501-505, 2009.

[20] S. A. Kim, Y. W. Zhu, S. G. Lee, S. Saha, and Y. H. Cho, "Electromagnetic normal force characteristics of a permanent magnet linear synchronous motor with double primary side," IEEE Trans. Magn., vol. 50, no. 1, art. 4001204, 2014.

[21] H. Zhang, B. Kou, Y. Jin, and H. Zhang, "Investigation of auxiliary poles optimal design on reduction of end effect detent force for PMLSM with typical slot-pole combinations," IEEE Trans. Magn., vol. 51, no. 11, art. 8203904, 2015.

[22] Y. Zhu, S. G. Lee, K. S. Chung, and Y. H. Cho, "Investigation of auxiliary poles design criteria on reduction of end effect of detent force for PMLSM,” IEEE Trans. Magn., vol. 45, no. 6, pp. 2863-2866, Jun. 2009.

[23] K.-B. Jang, J.-H. Kim, H.-J. An, and G.-T. Kim, “Optimal design of auxiliary teeth to minimize unbalanced phase due to end effect of PMLSM,” IEEE Trans. Magn., vol. 47, no. 5, pp. 1010-1013, 2011.

[24] Y. Zhu, D.-H. Koo, and Y.-H. Cho, "Detent force minimization of permanent magnet linear synchronous motor by means of two different methods," IEEE Trans. Magn., vol. 44, no. 11, pp. 4345-4348, 2008.

[25] N. Xi, J. Yang, Y. Cheng, and S. Zhu, "Detent force analysis and structure improvement of PMLSM," in Proc. Int. Conf. on Consumer Electronics, Communications and Networks (CECNet), 2011, pp. 260263.

[26] M. Y. Wang, L. Y. Li, and D. H. Pan, "Detent force compensation for PMLSM systems based on structural design and control method combination," IEEE Trans. Ind. Electron., vol. 62, no. 11, pp. 68456854, Nov. 2015.

[27] J. Zhao, H. Hu, X. D. Liu, Z. X. Gu, Z. Chen, "Influence of edge permanent-magnet shape on performance of an arc-linear permanent magnet synchronous machine," IEEE Trans. Magn., vol. 51, no. 11, art. 8112804, Nov. 2015. 